\title{
El agua y las raíces. Las Antigüedades Mexicanas y su recepción en el pensamiento historiográfico-educativo mexicano (1570-1945)
}

Water and Roots. Mexican Antiquities and their Reception in Mexican Historiographical-Educational Thought (1570-1945)

Pólux Alfredo Garcia Cerda ${ }^{1}$

\section{Resumen}

En el presente artículo se propone estudiar el pasado del campo historiográfico-educativo mexicano. Algunos especialistas han señalado que los orígenes de éste se ubican a finales del siglo XIX, sin embargo, se puede rastrear un pensamiento historiográfico-educativo previo a este momento. En ese sentido, ¿cuál habría sido su función social? ¿Qué autores, textos y objetos de estudio se considerarían para una historia de los antiguos historiadores de la educación en México? A continuación, presentamos un bosquejo de interpretación histórica cuyo fin es confirmar o refutar la hipótesis de que la recepción de las llamadas Antigüedades Mexicanas constituye un primer objeto de la historiografía de la educación en México. Desde un diálogo de saberes historiográficos, pedagógicos y hermenéuticos, el bosquejo propone identificar las huellas de un pensamiento historiográfico-educativo propio.

Palabras clave: historiografía de la educación, pensamiento historiográfico mexicano, historiografía novohispana, investigación histórica, historicidad del campo historiográfico

\section{Abstract}

In this article it is proposed to study the past of the Mexican historiographic-educational field. Some specialists have pointed out that the origins of this field are located at the end of the 19th

${ }^{1}$ Facultad de Filosofía y Letras, Universidad Nacional Autónoma de México, México. Correo electrónico: polux.gc@outlook.es 
century, however, a historiographic-educational thought can be traced prior to this moment. In that sense, what would have been its social function? What authors, texts, and objects of study would be considered for a history of the ancient historians of education in Mexico? Next, we present a sketch of historical interpretation whose purpose is to confirm or refute the hypothesis that the reception of the so-called Mexican Antiquities constitutes a first object of the historiography of education in Mexico. From a dialogue of historiographic, pedagogical and hermeneutical knowledge, the sketch proposes to identify the traces of a historiographic-educational thought of its own.

\section{Keywords: historiography of education, mexican historiographic thought, novohis- panic historiography, historical research, historicity of the historiographic field}

\section{Introducción}

Desde los inicios de la Nueva España, hubo letrados castellanos interesados en dar a conocer en Europa una cultura desconocida por lo que registraron sus interpretaciones sobre el pasado de los conquistados en las Ilamadas Antigüedades Mexicanas. Materialmente, ellas consistían en restos geográficos, políticos, económicos, sociales y culturales que ofrecieron representaciones gráficas, testimonios vivos y fuentes históricas cuya historicidad da cuenta de la formación de la conciencia histórica de una nación en relación con las culturas indígenas. Su conservación fue protagonizada por coleccionistas, bibliófilos y precursores de la antropología y la historia quienes incitaron diversas actitudes. Por un lado, discriminación, eurocentrismo y sentimientos de inferioridad/superioridad (hispanismo, en el caso del primero, e indigenismo, en el caso del segundo). Por otro lado, valoración de culturas distintas, la construcción un patrimonio histórico y cultural y el estudio del pasado de una nación pluriétnica.

Historiadores y antropólogos como Miguel León-Portilla (2011) y Miruna Achim (2014) han estudiado las Antigüedades Mexicanas en torno a la conformación del campo historiográfico mexicano. No obstante, hasta se desconoce su vinculación en la conformación del campo historiográfico-educativo, cuyo pasado ha sido poco estudiado por la comunidad de investigadores que lo integran. Entre los contados aportes, se suele indicar que el campo se consolidó en la segunda mitad del siglo XX, añadiendo que tal proceso se puede ubicar a principios de ese siglo. En el presente texto proponemos rastrear el pasado del campo algunos siglos antes, pretendiendo identificar las líneas de una incipiente y discontinua tradición de historiadores de la educación que tenían entre sus prioridades las de comentar obras, confrontar las fuentes y analizar juicios provenientes de discursos histórico-educativos.

Ante la inexistencia de semejante tratamiento analítico, se ofrece un esquema interpretativo planteado en tres movimientos: primero, se problematizará una idea de las Antigüe- 
dades Mexicanas como objeto historiográfico; después, se mostrará la posibilidad de interpretarlo como indicador de un horizonte de pensamiento sobre la escritura históricoeducativa mexicana; finalmente, se configurará un mapeo que señale rutas para futuras investigaciones. El esquema propuesto se basará en una perspectiva de Historia de las Ideas educativas (García, 2019: 39) cuyo fin es comprender la función social de las ideas según su historicidad. En torno a las Antigüedades Mexicanas, su función dependió de cómo fueron recibidas por generaciones de historiadores interesados en comprender la educación como fenómeno histórico y estudiar la forma en que se escribieron discursos de ese tipo. Cada autor tuvo su propia interpretación de la idea, porque fue pensada con intencionalidades distintas. En ese sentido, este esquema no pretende ser exhaustivo y se limita a problematizar una ruta de navegación histórica basada en una selección de textos pertenecientes a los siglos XVI, XVII, XVIII, XIX y principios del XX.

Justamente, en la década de 1940, especialistas con un ethos (o identidad profesional) iniciaron la consolidación de los estudios históricos en México (Matute, apud Carbonell, 1999: 415-440). En las décadas posteriores, los historiadores profesionales fueron habitando espacios como El Colegio de México (COLMEX), la Universidad Nacional Autónoma de México (UNAM), el Instituto Nacional de Antropología e Historia (INAH), el Instituto Politécnico Nacional (IPN), la Escuela Normal para Maestros (ENM), etc. Los formadores de los primeros historiadores fueron connacionales y transterrados, cuya labor rehabilitó espacios como el Archivo General de la Nación (AGN) y creó otros como el Archivo Histórico de la UNAM (AHUNAM). Si bien, cada institución configuró sus propios relatos sobre la génesis de los estudios históricos, el gran hito fueron unos cursos impartidos por Jesús Galindo y Villa en el Museo Nacional (Matute, apud Carbonell, 1999: 417). A principios del siglo XX, esta institución fue promovida por el régimen porfirista como un espacio oficial de donde procedía el monopolio legítimo del Estado sobre el pasado nacional (López Caballero, apud Escalante, 2011: 140).

Aunque la historiografía es una disciplina moderna, no se produjo ex nihilo. El legado que recibió el Museo Nacional hundía sus raíces más allá del siglo XX, de modo que los historiadores de profesión heredaron, de generaciones antiguas de historiadores, el oficio para estudiar y orientar la relación de los mexicanos con su pasado. Aquellos cursos de Galindo y Villa no tuvieron por objeto la historia de la educación, porque su intención no era esa. Sin embargo, el legado que recibió si contenía ideas, obras y fuentes sobre el estudio del pasado educativo. Por lo tanto, la escritura de la historia de la educación tampoco se produjo ex nihilo.

Aquel legado estaba integrado por historiadores, antropólogos y arqueólogos empíricos pero eruditos en la historiografía de su tiempo. Para ellos, las Antigüedades Mexicanas eran clave para elaborar una historia nacional. Sin tener una definición precisa de ellas, entre los 
siglos XVI y XIX todos coincidieron en que eran conjuntos de restos materiales pertenecientes al pasado indígena (monumentos, códices, obras pictóricas, utensilios, etc.). Desde los inicios de la vida novohispana, estos restos eran tan codiciados para estudiarse, coleccionarse o comercializarse, que se fueron integrando muchos objetos a distintas colecciones privadas:

Hombres y culturas de América en especial las altas culturas de Mesoamérica y los Andes fueron estudiadas como realidades comparadas, con las antiguallas de griegos y romanos. [...] Al mismo tiempo que se desarrollaba un proceso de catequesis y cristianización de las naciones del Nuevo Mundo, se emprendía una singular tarea abierta a la comprensión integral de la naturaleza y el hombre de América (Hernández, apud Hernández, 2001: 8)².

A través de los siglos, las Antigüedades provocaron discusiones de todo tipo, ya sea por la forma en que fueron obtenidas (desde expediciones científicas aprobadas por la Corona hasta el saqueo y contrabando sistemático de la piratería), por su significado (desde el eurocéntrico exotismo hasta el interés legítimo por comprender una cultura distinta a la europea) o por su valor (desde pensarse como símbolo de una especie de prehistoria hasta convertirse en patrimonio de la nación) (Escalante, 2011). En la selección, estudio y conservación de estos objetos estuvieron involucrados cronistas, bibliófilos, viajeros, políticos y empresarios, tal que los nombres de Fuenleal, Lord Kingsborough, Chavero y más se vincuIaron en su historia. No obstante, desde el siglo XIX, se pensó que las Antigüedades Mexicanas debían resguardarse en espacios adecuados, como el Museo Nacional:

El 16 de noviembre de 1827, el gobierno de Guadalupe Victoria promulgó un decreto
que prohibía la exportación de plata -en forma de polvo, mineral o lingotes- y de
antigüedades, así como la participación de extranjeros en la excavación de sitios
antiguos [...]. En principio, tanto la excavación como la conservación de las antigüedades
serían tareas del Museo Nacional de México, fundado en 1825; para éste por múltiples
razones -que incluyeron la inestabilidad política del país, la falta de recursos humanos
o materiales y la corrupción y el desinterés por parte de algunas autoridades- la ley
sería extremadamente difícil de ejecutar. Así lo reflejan las quejas de los directores del
Museo, en tanto las antigüedades mexicanas eran llevadas fuera del país, o en el caso
de los expedientes de adquisición de museos europeos, de importantes colecciones
privadas de antigüedades prehispánicas. Por su parte, los coleccionistas extranjeros
invocaban irónicamente al decreto prohibitivo, para agilizar la venta de sus objetos
importados a Europa, bajo el argumento de que dicha ley haría imposible la reco-
lección y exportación de antigüedades (Achim, apud Achim y Podgorny, 2008: 100).

${ }^{2}$ Las cursivas son de la autora. 
Más allá del complejo destino y valor para la memoria histórica nacional que tuvieron estos objetos, nos interesan textos de varias temporalidades en los se tomó a las Antigüedades Mexicanas como objeto de estudio. Las marginales reflexiones teóricas, metodológicas y filosóficas que estarían en esos textos permitirían comprender la historicidad de un pensamiento historiográfico-educativo propio (Cfr. Romero, 2008: 77). El actual campo historiográfico-educativo mexicano les debe mucho a investigadoras como Susana Quintanilla, Pilar Gonzalbo, Dorothy Tanck, Mílada Bazant, etc. Pero, ¿quiénes fueron nuestros antiguos historiadores de la educación? Nuestra hipótesis es que, así como un árbol vive de lo que tiene sepultado, aquel campo habría florecido por el tiempo que les tomó a las raíces para fijarse en el subsuelo. Este tiempo, previo a la profesionalización y la institucionalización, habría equivalido a un lento desarrollo de ideas y prácticas vinculadas a la experiencia del historiador de la educación. Al agua que el agua y las raíces, un pensamiento historiográficoeducativo mexicano previo al siglo XX pudo haber tenido una función similar al campo historiográfico-educativo actual.

Metodológicamente, el siguiente esquema interpretativo se basa en tres premisas: 1) la historiografía de la educación es un campo de saberes híbridos y sus constructores (historiadores de profesión y estudiosos de la educación -pedagogos, normalistas, etc.-) luchan por hacerlos legítimos; 2) la historicidad del pensamiento que nutre a dicho campo no puede comprenderse si desconocen las circunstancias que generaciones de historiadores lo han recibido y reelaborado en función de crisis político-culturales; 3) su estudio se basa en la interpretación de textos, los cuales son producto de intencionalidades (la del autor, la del lector y la de la obra) que deben ser situadas según su contexto (García, 2020: 40). Planteada la ruta metodológica, comenzamos con una pregunta de investigación.

\section{1. ¿Existió un pensamiento historiográfico-educativo mexicano?}

En la década de 1990, miembros del Consejo Mexicano de Investigación Educativa (COMIE) organizaron el primer estado del conocimiento del campo historiográfico-educativo. En el documento final se publicaron algunas reflexiones y un consenso sobre la génesis del campo. Con un relativo reconocimiento institucional, la profesionalización del historiador de la educación fue paralela a la profesionalización de los estudios históricos:

Débil, negada por la academia y sin soportes institucionales, la historiografía de la educación mexicana, existente en nuestro país por lo menos desde finales del siglo XIX, subsistió gracias a la labor de unas cuantas personas (Alberto Bremauntz, Isidro Castillo, Luis Chávez Orozco, y Luis G. Monzón, entre otros), quienes legaron a los 
historiadores de hoy una herencia aún no del todo valorada. Se trata de personas que no recibieron una formación historiográfica formal (Quintanilla, et al., 1995: 130).

Ninguna interpretación historiográfica está exenta de leerse históricamente, pues la crítica señala lagunas o vetas no atendidas. Al respecto surgen dos conjeturas: 1) la obra de los pioneros subyace en el olvido, por lo que nos sumamos a la necesidad de estudiarlos; 2 ) con base en ello, fue fundamental en la consolidación del campo instaurar desde los setentas una sólida tradición de investigación educativa, deudora de los saberes de sus herederos:

\begin{abstract}
A partir de los años cuarenta, la historia se instituye como tarea académica y como formación profesional. La investigación se nutre de marcos teóricos (básicamente marxismo, historicismo y positivismo). Se fundan institutos, centros de investigación y escuelas (El Colegio de México, Instituto de Investigaciones Históricas-UNAM y Escuela Nacional de Antropología e Historia) y se fundan espacios específicos para el debate entre profesionales de la historia, en éstos destaca la participación del exilio español y los fundadores mexicanos de la tradición historiográfica mexicanista como José María Iglesias, Silvio Zavala, Luis Conzález y González, Edmundo O ' Corman, entre otras (Arteaga, apud Aguirre y Cantón, 1999: 76).
\end{abstract}

Al reconocer la validez histórica de los juicios de Susana Quintanilla, validamos el consenso de nuestro legado, pero coincidimos con Belinda Arteaga en que la dimensión de la deuda podría ser mayor, incluyendo, además de los pioneros mencionados, a historiadores transterrados. Esto vislumbra la posibilidad de ampliar la tradición del campo a actores de formación universitaria. El consenso, en el que "a partir de 1940, mexicanos y transterrados se dedicaron, como nunca antes en México, a investigar, enseñar, traducir y editar" (Matute, 2015: 28), se basó en una tesis historicista fundada en el análisis crítico de las ideas históricas. Quien formuló esta tesis, Álvaro Matute, la recibió y actualizó de su maestro, Juan Ortega y Medina, quien en Polémicas y ensayos mexicanos en torno a la Historia compiló y comentó textos del pensamiento historiográfico mexicano entre 1824 y 1936 . Si el consenso reconoce la función del historiador formado en la universidad, ¿por qué en aquel estado del conocimiento se aminoró la presencia de historiadores de la educación con formación universitaria?

Inspirados en aquella tesis historicista, sería posible rastrear textos historia de la educación, aunque estuvieran al interior de obras de historia política, económica, social y cultural. Esto permitiría refutar el juicio de que la antigua historiografía de la educación, escasa en comparación con las demás historias, "se orientó hacia la elaboración de monografías, de carácter general o por periodos tomados de las historias nacionales" (Quintanilla, et al., 1995: 130-131). Por escasa que fuera, validamos la duda y afirmamos que hasta una monografía habría tenido 
un rudimentario marco historiográfico. Así, el estudio de un pensamiento historiográficoeducativo mexicano exige un análisis de largo alcance sobre el sentido político de la tradición universitaria dedicada a la historia de la educación. Por la historicidad de esta tradición, la búsqueda se puede iniciar antes del siglo XIX.

En el texto "De cómo el pasado prehispánico se volvió el pasado de todos los mexicanos" (Escalante, 2011), Paula López Caballero afirmó que en cuatro siglos de estudio del pasado indígena ha habido una transición cualitativa fundamental, de concebirla como prehistoria hasta reconocerla oficialmente como patrimonio nacional. En el presente artículo queremos rescatar el término prehistoria con un significado distinto al historiográfico y antropológico que se le ha dado, más allá de la concepción de un pasado glorioso, de la historia de bronce y de los excesos de las tesis indigenistas e hispanistas: como un periodo prefigurador de un campo epistémico y profesional. En estricto sentido, los estudios históricos recientes se formalizaron en el siglo XX, aunque el proceso inmediato se remonta al siglo XIX, cuando el moderno Estado-Nación atribuye a la escolarización como una vía efectiva para asegurar el monopolio político, económico, social y cultural a través de la formación de hombres de academia en las modernas universidades (Cfr. Moreno y de los Arcos, 1993: 90).

Los campos profesionales, como el de la historiografía de la educación, se consolidaron hasta la creación de licenciaturas en Historia, Antropología y Pedagogía, en un proceso simultáneo a la fundación de Centros de investigación que ofrecieron una relativa estabilidad laboral a los contemporáneos historiadores de la educación. Sin negar el consenso de la génesis del campo historiográfico-educativo mexicano (fijado en el primer estado del conocimiento), proponemos, desde una mirada de largo alcance, plantear la existencia de una historia previa a dicha historia, que no puede ser considerada significativamente menor sino distinta, porque su estudio vislumbra la necesidad de comprender la historicidad del campo más allá del consenso. A través de este razonamiento inicial, proponemos la categoría de prehistoria de la historiografía de la educación. Temporalmente, esta categoría pretende abarcaría tres grandes épocas (Colonización, Ilustración y Nación independiente), de las cuales derivaría una periodización de obras historiográficas escritas en función de un objeto de estudio:

1) Temprana Prehistoria o formación de las Antigüedades Mexicanas (siglos XVI y XVII). Este periodo conjunta obras de historiadores novohispanos que registraron sus interpretaciones sobre la vida histórico-educativa (concretamente sobre el pasado que llamaron mexicano).

2) Alta Prehistoria o primera recepción de las Antigüedades Mexicanas (siglos XVII y XVIII). Comprende la asimilación y reinterpretación criollista de fuentes primarias sobre el pasado mexicano y bajo un relativo nacionalismo. 
3) Baja Prehistoria o segunda recepción de las Antigüedades Mexicanas (siglos XIX y XX). Comprende la compleja constitución de una historiografía de la educación de corte liberal.

La distinción de cada etapa dependería de una crisis que la caracterizaría: la primera como dominación paulatina de Mesoamérica e instauración de un orden colonial, la segunda como transición del antiguo régimen al moderno Estado-Nación y la tercera como consolidación de un industrializado y contradictorio proyecto civilizatorio. Para Romero (2008: 95), en el Medievo se prefiguró la cultura moderna y, desde ella, se reelaboró el saber histórico que respondía a crisis político-culturales. Inspirados en esta idea, concebiremos a la prehistoria de la historiografía de la educación como una prefiguración del campo conformado por historiadores de la educación cuya cultura moderna habría sido producto de una reelaboración de saberes histórico-educativos que respondieron a crisis educativas propias de cada época. Retomando la clásica división histórica de la Edad Media (Temprana, Alta y Baja) trabajada por Romero (2013), aplicaremos nuestro esquema a una selección de textos donde se pensó la escritura histórica sobre el devenir de instituciones educativas, la organización de los estudios, los materiales didácticos y las técnicas de estudio usadas en la vida mexicana pasada.

\section{Primer momento. Temprana Prehistoria o de las Antigüedades Mexicanas (1570-1640)}

A finales de abril de 2010, Matute impartió el curso Historia de la escritura de la historia en México3. Basado en la idea gaosiana de historia de la historia de la historia (Matute, 2015: 230), su módulo uno se llamó "La historia de tradición indígena. Primera parte". Ahí expresó que, más allá del prejuicio eurocéntrico de los llamados pueblos sin historia (en tanto pueblos ágrafos), la Historia náhuatl existe y es distinta a la tradición occidental:

Tiene un punto de partida en la transmisión oral, aun cuando se trata de personas de la elite y no de un pueblo ágrafo o semi-ágrafo, sino que estamos en un ámbito de civilización total. Me voy, entonces, al tiempo prehispánico. Desde hace ya muchos años, Miguel León-Portilla [...] nos ha hablado mucho de la colaboración entre el tlacuilo y el tlamatini, el sabio y el escribano. Esto hace que se conjugue un saber que queda en una expresión gráfica, el códice, o que hemos convenido en denominar códice, que es una escritura pictográfica que sirve como ayuda de memoria. Incluso en uno de sus textos, relativamente recientes el propio Miguel León-Portilla se refiere a esto como soporte, utilizando la palabra moderna computacional. La escritura del tlacuilo era un soporte, una ayuda de memoria, que le servía al sabio, al tlamatini, como apunte para reproducir verbalmente o en su pensamiento el contenido de esa escritura.

\footnotetext{
3 Todos los módulos de este curso están disponibles en: https://grandesmaestros.unam.mx/curso/historia-de-la-escritura-de-la-historia-en-mexico/\#1559174071932-780dad76-24a00166-044b (fecha de consulta: 01/04/2020).
} 
Esto [...] desmiente al celebérrimo Voltaire que decía que los americanos no sabían escribir, no conocían ninguna manera de escritura" (Matute, 2010: 09:30-11:35).

La idea fue tomada de Los antiguos mexicanos a través de sus crónicas y cantares (1961), texto en el que Miguel León-Portilla buscó reconstruir una imagen fidedigna de la cultura mexica basada en testimonios indígenas. Para ello, defendió la forma mesoamericana genuina de registrar hechos históricos. Los precisos cómputos de tiempo eran sus mecanismos de validación, pues se basaban en el tiempo mítico y un pensar antropológico-místico que daba sentido histórico al ser mexica:

\begin{abstract}
Poseedores los antiguos mexicanos de conciencia histórica, como lo prueban sus códices y tradiciones, serán fundamentalmente sus propios testimonios los que guiarán este acercamiento a su pasado cultural. Dichos testimonios se conservan en el idioma hablado por los aztecas y sus varios precursores, o sea el náhuatl, conocido también como "mexicano" o "azteca". [...] La presente imagen del México Antiguo se debe a quienes nos legaron el tesoro documental de las fuentes indígenas: los sabios precolombinos, los maestros de los centros educativos del gran mundo náhuatl, los historiadores indígenas y aquellos que, aprendiendo el alfabeto castellano, transcribieron en su propia lengua los poemas y tradiciones, así como el rico contenido de sus códices [...] Sin descender a detalles nimios [...] se han elegido para reconstruir esta imagen varios rasgos fundamentales: la conciencia indígena de su evolución cultural; el modo como concibieron la tradición y la historia; la actitud de los aztecas, creadores de un misticismo guerrero y la de los seguidores de las antiguas doctrinas de origen tolteca" (León-Portilla, 2011: 7-8, 11-12).
\end{abstract}

Partiendo de una analogía (paideia fue para los griegos, lo que tlacahuapahualiztli-ixtlamachiliztli para los mexicas), nuestro humanista usó categorías historiográficas como conciencia histórica, tradición, historia y legado cultural de una civilización originaria. Una de las fuentes usadas para sostener su tesis fueron los Huehuetlatolli. Transmitidos oral y generacionalmente, los discursos de los sabios (o palabra antigua) tenían un pensamiento antropológico, ético, poético, educativo y jurídico tan complejo como el de otras civilizaciones originarias. Los sujetos de estos discursos fueron los Tlamatinime (que Sahagún llamó sabios o philosophos) y quienes los registraron fueron los tlacuiloque. Desde Filosofía náhuatl estudiada en sus fuentes (1959), se sostuvo la tesis de concebir a los sabios nahuas como filósofos, destinándoles, incluso, cualidades de pedagogos (León-Portilla, 2017: 112). En ese sentido, se nos presenta la siguiente hipótesis: si la función de historiador pertenecía al tlacuilo, y éstos registraron la interpretación de pasado educativo legada por los tlamatinime, luego, ¿los tlacuiloque fueron historiadores de la educación nahua? Dejando la labor a un experto en lengua, historia y cultura náhuatl, es preciso reconocer otras historicidades, como la del 
mundo náhuatl (Navarrete, 1999: 252) que Matute y León-Portilla señalaron: los relatos históricos sobre sobre los orígenes nahuas se concentraron en su Itoloca ("tradición") y se codificaron en un soporte llamado Xiuhámatl ("anales"). A ello, añadiríamos que dicho soporte era un material didáctico en el Calmécac. Al imponerse el orden colonial, Itoloca y xiuhámatl, junto con códices como el Mendocino, fueron clasificadas en el rubro de Antigüedades Mexicanas. Así, bajo esta denominación se guardaron los primeros indicios de la vida histórico-educativa nahua.

La instauración del nuevo orden exigía estrategias de control social. Por ello, se impuso una división político-cultural de dos Repúblicas, una de indios y otras de criollos (Gonzalbo, 1990: 20). Siendo la evangelización como estrategia civilizatoria predilecta, la Corona patrocinó, en un primer momento, el conocimiento de instituciones, ritos, ceremonias, costumbres y estratificación social. Después de ser entendidas, deberían sustituirse o subordinarse en un magno proyecto educativo dirigido por letrados formados en Universidades como la Salmantina o la de Alcalá (González, 2017: 39). Algunos frailes comenzaron a valorar la cultura mesoamericana como tal y, sin desatender la misión evangelizadora, realizaron investigaciones precursoras de la antropología y la historia. Frailes y laicos novohispanos escribieron crónicas y otras obras de carácter histórico. Después de cotejar fuentes, escribieron estos discursos según su noción de verdad histórica (algunos como testigos y otros como analistas de testimonios). Si en ellas incluyeron sus percepciones sobre el pasado educativo indígena, ¿ellos pueden ser considerados como los primeros historiadores de la educación mexicana? Para resolverla, señalamos seis primeros textos: 1) Historia general de las cosas de la Nueva España (1570), del franciscano Fray Bernardino de Sahagún (c1499-1590); 2) Antigüedades de la Nueva España (c1574), del médico real Francisco Hernández (c15141587); 3) Historia de las Indias de Nueva España e islas de la tierra firme (1579), del dominico Fray Diego Durán (1537-1588); 4) Historia natural y moral de las Indias (1590), del jesuita José de Acosta (1540-1600); 5) Historia eclesiástica indiana (1597), del franciscano Jerónimo de Mendieta (1525-1604) y, 6) Historia de la nación chichimeca (c1610-1640) del historiador Fernando de Alva Ixtlilxóchitl.

En un primer analítico, estas obras contienen diversas interpretaciones sobre las tres grandes instituciones educativas nahuas: la familia, el Calmécac y el Telpochcalli. En un segundo nivel, describieron los contenidos que se enseñaban: historia, medicina, astronomía, matemáticas, filosofía, etc. En un tercer nivel, más difuso que los anteriores, se registraron técnicas y materiales didácticos, como el comentario de códices y los mitos (Sahagún, 1938: 288-300; Hernández, 2001: 66-71; Durán, 1880: 106-118, 225-233; Acosta, 1590: 444-446; Mendieta, 1870: 111-128). Alva Ixtlilxóchitl (1975: 96-98) describió una "Universidad" que llamó "Casa de Nezahualcóyotl" y también un Tlacateo o centro educativo de príncipes. 
Al final, cada autor tuvo su noción de vida histórico-educativa indígena, aunque seguro coincidían que pertenecían a las Antigüedades Mexicanas, por ser vestigios del mundo que debía sucumbir. Pero hubo instituciones educativas que se resistieron a dejar morir ese mundo, como el Colegio de Santa Cruz de Tlatelolco. Los saberes históricos ahí estudiados, junto con los obtenidos de expediciones científicas, sirvieron para prefigurar una primera generación de historiadores de la educación. El embrionario corpus de obras, o fragmentos de obras, tuvo estilos y tramas muy distintas entre sí. Algunas interpretaciones nacían del concepto de idolatría, profundamente eurocéntrico pero propio de su tiempo. Otras más se atrevieron a comparar, incluso a cuestionar, la educación europea como única forma de vida civilizada y reconocieron los avances en materia educativa de los mesoamericanos. Si Sahagún, Hernández, Durán, Acosta y Mendieta fueron historiadores, y estos interpretaron la vida históricoeducativa mesoamericana cotejando fuentes y comentándose entre ellos, es válida la atribución de primeros historiadores de la educación mexicana (recordemos que mexicanos eran los habitantes de México-Tenochtitlán, incluyendo, en un primer momento a los indios; después pasó a ser gentilicio de la colonial Ciudad de México construida encima de la ciudad mexica).

Los mexicanos fueron reconocidos jurídicamente como vasallos de la Corona y debían ser adoctrinados como cualquier persona de su estamento. Uno de los dilemas más difíciles que vivieron los primeros evangelizadores fue enseñar la fe cristiana en lengua castellana o en lenguas indígenas (generalmente, se optó por el náhuatl o mexicano, y el otomí, siendo ambas las más habladas en el Ciudad de México y alrededores). Aunque primero se promovió el estudio y enseñanza de la doctrina en lenguas indígenas, más tarde, en un ambiente contrarreformista anti-judío y anti-luterana, las autoridades eclesiásticas acordaron reafirmar los dogmas únicos de la fe enseñándolos sólo desde un idioma, el castellano. Este segundo momento promovió la censura de todo estudió de la cultura mesoamericana, incluyendo su pasado educativo mesoamericano. Así, se impusieron como únicas a las primeras interpretaciones que juzgaron a aquella cultura como puramente idolátrica y diabólica.

En este hostil contexto, el interés por las Antigüedades Mexicanas decayó, aunque había un espacio escolar que lo podía mantener vivo: la cátedra de lengua mexicana y otomí. Ella se impartió en la Real y Pontificia Universidad de México, una corporación cuya función era formar escolásticamente a la élite letrada. Además de Gramática, Retorica y Lógica (que conformaban el Trivium en la Facultad de Artes Menores), se impartían estudios de Leyes, Cánones, Medicina y Teología. La cátedra de lengua mexicana y otomí innovó la organización de estudios universitarios, pero a diferencia del Colegio de Tlatelolco, no tuvo el mismo estatus académico que las demás cátedras. Aun así, se impartió lengua mexicana y otomí porque era probable que el egresado de la universidad obtuviera una canonjía en los alrede- 
dores de la Ciudad de México. Si en estos lugares predominaba el náhuatl u otomí, la formación universitaria debía atender esta necesidad.

La cátedra se propuso oficialmente en la legislación educativa de la Real Universidad, cuyo documento rector, las Constituciones, fungía como un plan de estudios. Entre los catedráticos y los clérigos más poderosos que integraban el Claustro universitario, hubo oposición a la enseñanza de la cátedra, prefiriendo apegarse al dogma contrarreformista y a la ortodoxia de las Constituciones salmantinas (Conzález, 2017: 26). A principios del siglo XVII, con un renovado apoyo en las Constituciones de Marqués de Cerralvo, la cátedra se aprobó por primera vez. Incluso se prescribió como texto base a Arte de la Lengua Mexicana de Fray Alonso de Molina (Albiñana, apud Ruiz, 1998: 46). Entretanto, la cátedra no se habilitó su impartición hasta las Constituciones de Juan de Palafox, Obispo y reformador de la Real Universidad:

Constitución 119 / Otra cáthedra de lengua mexicana, de propiedad, con salario de trescientos pesos cada año, en quitas y vacaciones, la qual se entienda vacar siempre que el que la leyere, siendo clérigo, pasare a beneficio, o religiosos, a priorato o doctrina; que se a de leer desde las ocho hasta las nueve de la mañana, y desde las tres hasta las quatro de la tarde; por la mañana, lengua mexicana y por la tarde otomí. ${ }^{4}$ [...] Constitución 179 / Y para la cáthedra de lengua mexicana y otomí, se han de señalar puntos en un misal para predicar un sermón de cada lengua del evangelio que sorteare el opositor. [...] Constitución 232 / Ordenamos que en la cáthedra de lengua mexicana y otomí voten todos los maestros y doctores graduados e yncorporados en esta universidad; y se les encarga la conciencia que se ynformen de personas peritas en dicha lengua que asistan a oyr los dichos actos, quién es el más eminente de los opositores y que la sabe con mayor perfección, cuidando de que no solamente sepa el que llaman tianguiztlatoli, que es en lenguaxe común, sino el teotlatolli, que es el que mira a los misterios divinos y primeros rudimentos de la fe (González y Gutiérrez, 2018: 115, 145 y 169$)^{5}$.

A pesar del impulso reformista de Palafox, la cátedra tuvo otro obstáculo para impartirse, pues el catedrático de lengua mexicana y otomí debía dominar simultáneamente ambas lenguas. Esto redujo el número de aspirantes a catedráticos e inhibió el interés por la cultura indígena. Sólo los agustinos cumplían el requisito en ambas lenguas, lo cual explica por qué

\footnotetext{
${ }^{4}$ En las Constituciones palafoxianas, versión de 1775, se puede leer la "Nota 24": "Esta cátedra no se vota en la real junta, como las otras, sino que se adjudica a quien en claustro adquiere mayor número de votos. Para las lecciones asisten dos jueces inteligentes en el idioma, y en ellas el exercicio principalmente se acomoda a demonstrar la habilidad de los sujetos concurrentes para aquellas funciones que son más esenciales y proprias en los ministros de la santa iglesia y se reputan más necesarias para instruir a los indios en el dogma y máximas sagradas del evangelio. Es Proprietaria por lo que mira a su duración, que se estiende hasta cuando dexa de vivir o la renuncia su poseedor. No es necesario en el optante grado mayor, ni aun el menor, según el tenor de la constitución, ni para optarla ni para mantenerse en su regencia" (González y Gutiérrez, 2018: 169)

5 Se respetó la grafía original.
} 
la cátedra perteneció a dos miembros de tal orden mendicante (Becerra 1963: 265). Además de ninguno de ellos escribió alguna obra como las de Sahagún o Hernández, el paulatino abandono de esta cátedra también significó abandonar un espacio en el que se habría podido estudiar el pasado educativo indígena, aunque hubiera sido marginalmente. Según Mendieta (1870), el libro de Molina era el mejor instrumento para comprender la cultura mexicana. Pasaron muchos años para que una nueva generación de historiadores novohispanos se abrieran paso en los siglos XVII y XVIII: 1) Parayso occidental (1684), de Carlos de Sigüenza y Góngora; 2) Bibliotheca Mexicana (1755), de José de Eguiara y Eguren; 3) Historia antigua de México (1780), de Francisco Javier Clavijero; 4) Tezcoco en los tiempos de sus antiguos reyes, ó sea, Relación toma de los manuscritos inéditos de Boturini; redactados por el Lic. D. Mariano Veytia. Publicalos con notas y adiciones para estudio de la juventud mexicana, Carlos María de Bustamante (1826). Contando o no con el apoyo de la Real Universidad, Sigüenza, Eguiara, Clavijero y Veytia inauguraron una nueva etapa del pensamiento historiográficoeducativo y se concibieron como lectores de los textos de Sahagún, Durán, Hernández, Acosta y Mendieta.

\section{Segundo momento. Alta prehistoria o primera recep- ción de las Antigüedades Mexicanas (1684-1826)}

En las obras históricas novohispanas del siglo XVII se relegó el saber histórico de la educación. La única excepción fue el humanista y científico Carlos de Sigüenza y Góngora. Amó tanto a la historia mexicana que arriesgó su vida cuando una turba de gente causó el motín de 1692. Esta rebelión provocó el incendio del palacio virreinal y el ayuntamiento, edificio en el que se conservaban documentos históricos y demás Antigüedades Mexicanas. Los objetos que Sigüenza rescató fueron donados al fallecer a los jesuitas, pero antes le sirvieron, junto con otros que se perdieron en el incendio, para escribir obras como Parayso oriental (1684). En esta historia del Convento de Jesús María le dedicó un capítulo a la educación impartida a sus alumnas, las nobles indígenas. Para ello, siguió la obra de Ixtlilxóchitl:

Concordaron los barbaros Mexicanos, con los Romanos antiguos en destinar Virgines puras, para que cuydasen de la perpetuidad del fuego; y como á unos, y otros los governaba vn impulso, con desechable diferencia, eran en vna, y en otra parte de las ceremonias las mismas. Deviole Mexico este nuevo estado de Virgines Sacerdotisas, al quarto de sus Reyes, el valeroso Itzcoatzin, que sin que se lo estorvasen los estruendos marciales, se ocupó diligente, en lo que miraba al servicio de los mentidos Dioses, fabricando á la espaldas de sus soberbios Templos, capassima habitacion, para que la ocupasen las Cihuatlamacazque, que assi quiso se llamasen estas Uestales Doncellas. (Sigüenza, 1995: fol. lv-2r). 
Imitando al historiador romano Tito Livio (2000: 1, 3-4), Sigüenza usó una analogía en este fragmento: las vestales fueron para la fundación de Roma lo que las vírgenes fueron para la fundación de México. Esta escritura histórica barroca combinó elementos historiográficos grecolatinos y novohispanos, porque las vestales eran sacerdotisas del Telpuchcalli y del Ichpuchcalli. Asimismo, distinguió dos figuras educadoras más, las cihuatlamacazque o sacerdotisas del Calmécac, y a las Ichpochtlatoque. Sin precisar los contenidos o métodos de enseñanza usados en esa institución, Parayso oriental y las Antigüedades Mexicanas que rescató Sigüenza fueron recibidas por un erudito novohispano. El teólogo y rector de la Real y Universidad de México, José de Eguiara y Eguren, autor de Biblioteca Mexicana (1755) en respuesta a un letrado europeo que menospreciaba la cultura novohispana.

En esta obra, Eguiara comentó las obras de la primera generación (Sahagún, Hernández, Durán, Acosta y Mendieta) junto con las de Ixtlilxóchitl y Sigüenza. De sus prólogos, destacan el II ("Pruébase cuán grande es la ignorancia del deán alicantino en punto a antigüedades mexicanas, y demuéstrase la ilustración de nuestros indios, trayendo a la palestra sus códices y bibliotecas"), el IV ("En el que se ponen de manifiesto algunos insignes monumentos que no sólo ilustran y corroboran cuanto precede, sino que hacen más patente la cultura de los antiguos mexicanos"), el V ("Testimonios de escritores muy autorizados traen a plena luz los colegios y centros de enseñanza de los indios y mexicanos") y el VI ("En el que se trata de la afición de los mexicanos por la poesía y la oratoria, se manifiesta su pericia en la medicina y se habla de las leyes que usaban, con otras pruebas de su inteligencia, expuestas brevemente") (Eguiara, 1986: 54-61, 69-79). Eguiara era muy cercano a los jesuitas, con quienes compartía el gusto por la renovación de la escolástica y la fe, sin desconocer el dogma de la cristiandad. Como precursor de la ilustración novohispana, incluyó en su Biblioteca Mexicana "a todos los hombres virtuosos quienes con el ejemplo de su vida eran los conductores y el espejo de la sociedad mexicana" (De la Torre, apud Eguiara, 1986: CXLIX).

La recepción de las obras históricas novohispanas, en especial de los jesuitas, comenzaron a integrar un naciente corpus bibliográfico de autoridades, textos y lugares comunes, con la salvedad de que la vida histórico-educativa de los nahuas ya tenía otro fin, la defensa de la cultura mexicana. El reto fue aceptado por historiadores jesuitas. Ellos modernizaron ideas, métodos y fines de la escritura histórica desde un relativo nacionalismo que registró la escritura histórica de la educación aludiendo a métodos, organización de estudios e intelectuales formados por la orden en obras como Historia antigua de México (1780).

Pero dejando por ahora las alabanzas que os son debidas [...] quiero quejarme amistosamente de la indolencia o descuido de nuestros mayores con respecto a la historia de nuestra patria. Cierto es que hubo hombres dignísimos que se fatigaron en ilustrar 
la antigüedad mexicana y nos dejaron de ella preciosos escritos. También es cierto que antes hubo en esa Universidad un profesor de antigüedades, encargado de explicar los caracteres y figuras de las pinturas mexicanas por ser tan importantes para decidir en los tribunales los pleitos sobre la propiedad de las tierras o la nobleza de algunas familias indias, y esto es puntualmente lo que me causa pena. ¿Por qué no se conserva aquel profesor tan necesario? ¿Por qué se han dejado perder aquellos escritos tan preciosos, y especialmente los del doctísimo Sigüenza? Por faltar el profesor de antigüedades no hay actualmente quien entienda las pinturas mexicanas, y por la pérdida de los escritos, la historia de México se ha hecho dificilísima, por no decir imposible. Ya que esta pérdida no se puede reparar, al menos que no se pierda lo que nos queda. / Yo espero que vosotros, que sois en este reino los custodios de las ciencias, tratareis de conservar los restos de las antigüedades de nuestra patria, formando en el magnífico edificio de la Universidad, un museo no menos útil que curioso, en donde se recojan las estatuas antiguas que se conservan o que se vayan descubriendo en las excavaciones, las armas, las obras de mosaico y otros objetos semejantes; las pinturas mexicanas esparcidas por varias partes, y, sobre todo, los manuscritos, así los de los misioneros y otros antiguos españoles, como los de los mismos indios, que se hallan en las librerías de algunos monasterios, de donde se podrán sacar copias antes de que los consuma la polilla o se pierdan por alguna desgracia. Lo que hace pocos años hizo un curioso y erudito extranjero (el caballero Boturini) nos indica lo que podrían hacer nuestros compatriotas, si a la diligencia y cuerda industria unieran aquella prudencia que se necesita para sacar esta clase de documentos de manos de los indios" (Clavijero, 1963: XVII).

La queja de este jesuita confirma cómo la Real Universidad de México se resistía a que se estudiara el pasado indígena. A falta de condiciones materiales, pero afín a Sigüenza y Eguiara, Francisco Javier Clavijero analizó y criticó la vida histórico-educativa nahua en el Libro VII, ("Educación de la juventud mexicana"). En esta ocasión, no intentaba refutar a un canónigo peninsular, sino a dos científicos europeos reconocidos: Cornelius De Pauw y Conde de Buffon. Para Clavijero si América tenía su propia historia y los criollos e indígenas eran americanos, eso les daba el derecho de propiedad sobre las tierras americanas, y fue la educación el medio que les enseñó a sembrar, abrir caminos y aprender oficios (Clavijero, 1963: 205-206). Esta actitud Ilamó la atención de sus contemporáneos eruditos novohispanos. Uno de ellos publicó "Notas críticas que escribió el Bachiller don José Antonio Alzate sobre la Historia Antigua de México del Abate don Francisco Javier Clavijero". Alzate se interesó en la obra del historiador jesuita y escribió notas historiográficas, dos de ellas eran de carácter historiográfico-educativo:

(21) Pág. 218. Hasta el día procuran los indios dedicar sus pequeños hijos a los colegios; si en el Real de San Gregorio de esta corte se recibiesen todos los que traen sus padres, no habría lugar suficiente para que habitasen ni rentas con qué alimentarlos. Muchos indios entregan también sus hijos a los españoles para que los eduquen. 
Para las becas que hay destinadas para indios en el Colegio Seminario son infinitos los pretendientes. Se ha intentado, promovido y conseguido a esfuerzos de viajes reiterados por el ejemplar don Cirilo, indio eclesiástico de Tlaxcala, la fundación de un colegio para indios: se ha dispuesto el plan, pero las dificultades promovidas han entorpecido el efecto de la real cédula [...] (22) Pág. 219. Al presente en Michoacán el fiscal, que es un indio nombrado por el cura, cuida de la juventud varonil, y las doncellas están gobernadas por la mujer del mismo fiscal (Moreno, 1972: 381).

Para Alzate y Clavijero, el indígena como sujeto histórico refutaba toda historia que reconociera sólo a Europa el centro económico, político, social y cultural. También se oponían al espíritu de las reformas borbónicas que imponían el castellano como idioma único y la supresión de las lenguas indígenas. En la misma línea, la obra histórica de otro jesuita, Mariano Fernández de Echeverría y Veytia, simboliza cierta continuidad política entre el pasado historiográfico inmediato (representado por el historiador y anticuario italiano Lorenzo Boturini) y su reelaboración historiográfica por Carlos María de Bustamante:

Las investigaciones de Boturini suscitaron la sospecha de las autoridades novohispanas que, tras descubrir que viajaba sin licencia, lo deportaron, no sin antes confiscar su colección. Su rico museo quedó, finalmente, en la Secretaría del Virreinato donde 'el descuido, la humedad, los ratones y los curiosos, lo menoscabaron notablemente.' Uno de esos curiosos fue el anticuario poblano Mariano Fernández de Echeverría y Veytia (1718-1780), quien transcribió muchos documentos, incluyendo los textos de Alva Ixtlilxóchitl. Un poco más tarde, el franciscano Manuel Vega aprovechó las copias realizadas por Echeverría y Veytia para incluirlos en la Colección de memorias de Nueva España destinada a la Real Academia de la Historia en Madrid. Una de las copias de esa Colección de memorias se guardó, con los restos del museo de Boturini, en la Secretaría del Virreinato. / Ahí fue donde Bustamante descubrió los textos de Alva Ixtlilxóchitl que luego incluyó en los artículos sobre "antigüedades mexicanas" que publicaba en el Diario de México, el primer cotidiano civil de la Nueva España, fundado por Jacobo de Villaurrutia y el propio Bustamante en 1805 con la misión de ilustrar a la ciudadanía (García Loaeza, 2007: 10).

La obra histórica de Veytia fue publicada por Bustamante, y ella incluyó algunos fragmentos sobre la vida histórico-educativa indígena. Entre las educadoras (como las vestales), los maestros, en esta obra se citaron algunos Huehuetlatolli. El fin era reivindicar el origen puro de una nación: "He aquí las bases de la educación mexicana. ¿Y a ésta nación se le ha Ilamado bárbara?" (Bustamante, 1826: 202-217). El discurso histórico fue usado políticamente para afirmar un pasado educativo mexicano antiguo o para negarlo en favor de la educación colonial, es decir, se vislumbraba un incipiente conflicto entre indigenistas e hispanistas, aunque a ninguno le importara realmente los sectores indígenas vivos. En las 
obras clásicas de la historiografía liberal (como la de Veytia) hallamos textos donde se pensó tal disyuntiva: 1) Obras de D. Lucas Alamán. Disertaciones sobre la historia de Méjico. Tomo III (1844); 2) Obras de Ignacio Ramírez. Tomo II. Economía política. Cuestiones políticas y sociales. Diálogos de "El Mensajero (1899); 3) "Carta a Mariano Riva Palacio" (1872), de Gabino Barreda; 4) Tratado elemental de pedagogía (1900), de Luis Ruiz; 5) "La educación nacional" (1902), Educación y evangelización (1942) y Las cuatro grandes crisis de la educación en México (1943) de Ezequiel Chávez. Esta tercera generación fue la más próxima a los estudios históricos recientes y accedió a otro tipo de saberes científicos y humanísticos.

\section{Tercer momento. Baja prehistoria o segunda recepción de las Antigüedades Mexicanas (1826-1945)}

El estudio de las Antigüedades Mexicanas fue muy discutido en los primeros años de vida independiente, cuando la escritura histórica liberal navegaba entre el monarquismo y el republicanismo, entre el centralismo y el federalismo. La inestabilidad política tuvo por correlato a una heurística dudosa en aceptar o rechazar el corpus historiográfico disponible. LA prioridad en las plumas de los historiadores de la educación en el siglo XIX fue el culto a la nación. Por un lado, Bustamante (1984: 303) tramó un relato nacionalista que idealizó al pasado educativo mexica como glorioso y puro: en su "Carta vigésima prima de un viajador por México" (1822) le llamó bárbaro al sistema de estudios universitarios colonial. Pero su labor destacó más por el rescate, edición y publicación de fuentes primarias: las Relaciones históricas de Ixtlilxóchitl (1829), la Historia general de Sahagún (1829) y Tezcoco en los últimos tiempos de sus antiguos reyes de Veytia (1826). Bustamante y el criollismo insurgente desdeñaron la formación colonial impartida en las escuelas de Primeras Letras y la Real Universidad de México (ahora convertida en Nacional). Por tal razón, la educación nahua se mostró como civilizada o, al menos, no corrompida como la educación europea. Pero no todos los políticos de su tiempo aceptaron esta interpretación monolítica del pasado educativo indígena.

Un ejemplo fue Historia de Méjico de Lucas Alamán, quien, sin mencionar a las Antigüedades Mexicanas, en la "Séptima Disertación" ("Establecimiento y propagación de la religión cristiana en la Nueva España") analizó el pasado educativo colonial. Su defensa de los jesuitas como propagadores de la ilustración (Alamán, 1899: 68-72), hizo que su discurso nacionalista, criollista y centralista diera sentido a una reforma educativa deudora del Ratio studiorum que formó la juventud y renovó los estudios. El triunfo de Juárez trajo consigo nuevas necesidades historiográficas. Su prioridad fue pensar una nueva imagen del pasado educativo que sintetizara la visión radical y la moderada (este proceso se instauró lenta y contradictoriamente hasta el régimen porfirista). El siglo XIX fue, por excelencia, el siglo del nacionalismo y uno de los objetivos del nuevo discurso histórico nacional fue hallar un pasado común: 
Los misioneros del siglo XVI recordaron preferentemente los hechos infames del estilo de vida prehispánica para facilitar su ruptura. Los criollos de la insurgencia de principios del siglo XIX le sacaron todos sus trapitos al sol a la época colonial, la desacralizaron, le exhibieron sus orígenes codiciosos. Los historiadores de la reforma liberal, al grito de borrón y cuenta nueva, pusieron como lazo de cochino la trayectoria vital de su patria [...] Nadie puso en duda en el siglo XIX lo provechoso de la historia de bronce (González, apud Pereyra, et al., 2002: 62 y 65).

El perfil de una memoria histórica nacional se afianzó con una broncínea educación nacional, por lo que la búsqueda de una historia nacional también pensó los siglos de vida educativa pasada hasta mediados de este siglo. Por su injerencia en las decisiones políticoeducativas, los dos icónicos historiadores liberales fueron Ignacio Ramírez y Gabino Barreda, uno como Ministro de Justicia e Instrucción Pública y el otro como fundador de la Escuela Nacional Preparatoria (ENP). La visión histórico-educativa de Ramírez se fijó en textos como Instrucción Pública (que exigía no repetir los errores del pasado educativo grecolatino), La enseñanza religiosa (una crítica al Catecismo de Ripalda como reliquia colonial) y Antigüedades Mexicanas (afirmando que la cultura pretérita debe resguardarse en un Museo Nacional bajo la consigna de que "la sabiduría nacional debe levantarse sobre una base indígena") (Ramírez, 1889: 193-209). A través de estos textos, aunado a su Proyecto de Creación de un Museo de Antigüedades Mexicanas, el fin era la reivindicación de los pueblos indígenas, de su cultura y su literatura, de allí la recuperación de las Antigüedades Mexicanas, patrimonio nacional que había sido propuesto por Alamán. Sobre la recepción de esta visión, un contemporáneo suyo, José María Vigil, publicó, en 1878, "Necesidad y conveniencia de estudiar la historia patria":

\footnotetext{
Desearíamos ardientemente que nuestra educación literaria y científica formara un carácter acendrado y profundo de mexicanismo; que nuestras antigüedades fuesen objeto de la más exquisita solicitud por parte de los gobiernos; que no se perdonara medio en su conservación y estudio; que el idioma nahoa figurase al lado de las lenguas sabias, a reserva de que cada uno de los Estados consagrase una atención especial a sus monumentos y lenguas particulares; y en una palabra, que la civilización de nuestros antepasados, más variada, más rica y más grandiosa bajo todos los aspectos de la sangrienta de las antiguas tribus del norte, fuese el fundamento de nuestros estudios históricos y literarios (Ortega y Medina, 1992: 267).
}

Ramírez y Vigil fueron desplazados poco a poco del plano político-educativo y el fervor positivista recogió su interés por las Antigüedades Mexicanas, aunque lo adaptó a un modelo educativo distinto. A diferencia de los liberales de la vieja guardia, la visión históricoeducativa de Barreda se basó en una compleja filosofía de la historia que aplicó a la historia de la educación en su "Carta a Mariano Riva Palacio" (1871). El entonces gobernador del 
Estado de México le solicitó un esquema para reformar los estudios preparatorios, en particular, al Instituto Científico y Literario del cual Ramírez llegó a ser su director. A grandes rasgos, la epístola expresó dos críticas a la educación virreinal, la primera fue contra la educación escolástica representada por la Universidad colonial y su monopolio de otorgamiento de grados. La otra se dirigió a la educación jesuita, afirmando que una verdadera educación liberal debía valorar, asimilar y superar al Ratio Studiorum como organización jurídica, administrativa, filosófico-educativa y técnico-didáctica de educación para la juventud (Barreda, 1992: 67). La instalación del Positivismo puso la primera piedra para profesionalizar a los primeros historiadores de la educación, de modo que, como paradigma historiográfico, proveyó teóricamente de la Ley de los tres Estados, metodológicamente del orden de las ciencias positivas y el Método Científico y, filosóficamente, de la noción de Progreso como fin social único (Cfr. Larroyo, 1978: 281-284).

Los primeros historiadores de la educación positivistas egresaron de la ENP e incluyeron en sus obras a fuentes históricas como el Códice Mendocino y textos como los de Chavero e lcazbalceta (Ruiz, 1986: 223; Chávez, 1994: 67 y ss., Larroyo, 1978: 67). Por su formación, estos historiadores ocuparon cargos políticos y administrativos, al mismo tiempo dirigieron las primeras cátedras de Historia de la educación: en 1878, Manuel Flores como docente de la Escuela Secundaria de Señoritas (Moreno, 1993: 105) y, en 1900, Luis Ruiz como autor del apartado XXI ("Historia de la pedagogía") de su Tratado elemental de pedagogía (Ruiz, 1986: 218 y ss.). Bajo el esquema positivista, Ezequiel Chávez escribió "La educación nacional" que se integró a la magna obra México. Su evolución social (1902), a cargo de Justo Sierra. Una obra de transición fue y Educación y evangelización (1942) haciendo uso de fuentes primarias y ofreciendo balances sobre las obras historiográficas escritas hasta el momento (incluyendo la Historia de Alamán y el Tratado de Ruiz).

Pero Chávez dio un giro a la historiografía historicista. Su labor heurística en la crítica de fuentes y su interpretación intuitiva tenía como finalidad penetrar en el sentido filosófico y místico de evangelizadores como Sahagún, Durán, Acosta y Mendieta. Con un estilo crítico, defendió la educación religiosa y sus convicciones liberales. Su obra historiográfico-educativa fue fruto de su labor universitaria como historiador de la educación a cargo de la cátedra de Ciencia y Arte de la educación, en la Escuela de Altos Estudios y, luego, en la Facultad de Filosofía y Letras. En tanto, su obra más crítica fue Las cuatro crisis de la educación en México a través de los siglos (1943), donde se pronunció contra el monopolio de la educación socialista al que responsabilizaba de una de las cuatro crisis (Chávez, 1967: 7 y ss.).

Las Antigüedades Mexicanas le dieron estatus a instituciones como el Museo Nacional, que dejó de ser un Gabinete de curiosidades. Mientras tanto, al interior de la UNAM, Chávez simboliza el umbral prehistórico de la historiografía educativa. Su amor por la vida históricoeducativa inspiró a uno de sus alumnos, Francisco Larroyo, para que publicara, en 1945, 
Historia comparada de la educación en México (Pérez, 1997: 46 y ss.). Oficialmente, es posible ubicar la fundación del campo a partir de una obra que se escribió desde la Escuela Normal de Maestros y la UNAM. Formado desde un largo y disruptivo curso temporal, la tradición que inició con la recuperación de las Antigüedades Mexicanas, finalmente se consolidó en el siglo XX desde espacios escolares como la asignatura de Historia de la educación en México (en los estudios pedagógicos y normalistas recientes) y de investigación como el Seminario Genealogía de Prácticas y Discursos en Educación (IISUE) y el Seminario de Pedagogía Universitaria (Colegio de Pedagogía). Crítico de este legado, fue el Seminario de Historia de las Universidades Hispánicas, pues su sólido grupo de investigadores gozan de prestigio en el campo contemporáneo, por su loable labor en el AGN y AHUNAM, y por su historia social de las universidades coloniales y modernas de México, Latinoamérica y del mundo.

\section{Reflexiones finales}

Las Antigüedades Mexicanas nacieron de una necesidad de la Corona por conocer y controlar la República de Indios para supeditarla a la de Criollos, pero los hallazgos de sus primeros historiadores dieron cuenta de una nueva mirada del pasado que contradecía el exotismo europeo. Una de sus facetas pertenece al estudio de la escritura histórico-educativa, tal que las fuentes históricas pensadas concordaron con las de la cultura mexica. Esto evidencia cierto centralismo, aunque se podría justificar en parte por la disponibilidad de fuentes y testimonios en ese tiempo. Políticamente, se usó este discurso histórico para generar sentimientos nacionalistas (o cuasi-nacionalistas) que fueron encauzándose después en un tipo de conciencia nacional o incipiente patriotismo criollo, que buscó los medios para instaurar un nuevo orden político, económico, social y cultural. En torno a las Antigüedades Mexicanas, hemos atestiguado que la Real Universidad de México pudo haber dado un espacio propicio para su estudio y hasta su conservación. Eso no sucedió. Lo paradójico es que la corporación educativa no brindó espacios para su estudio, aunque si influyó en la formación de algunos historiadores de Antigüedades Mexicanas. Como corporación de antiguo régimen, al fin y al cabo, la Universidad no brindó una cátedra a la altura de este objeto historiográfico. La única que pudo asemejar esta función fue la cátedra de lengua mexicana y otomí, pero la élite universitaria lo impidió constantemente. Sin condiciones epistémicas ni materiales para el estudio del pasado educativo, se formó una difusa tradición conformada, generacionalmente, por historiadores eruditos y empíricos que encontraron interlocutores coetáneos o recientemente fallecidos.

Nuestro esquema arrojó una clasificación de tres generaciones de historiadores de la educación mexicana: la primera, conformada por historiadores novohispanos del siglo XVI que disfrutó de un relativo apoyo de la Corona (Sahagún, Durán, Hernández, Acosta, 
Mendieta e Ixtlilxóchitl); la segunda, que encaró un ambiente contrarreformista y sobrevivió al difícil siglo XVII (Sigüenza) hasta reelaborarse en saberes históricos ilustrados del siglo XVIII (Eguiara, Clavijero y Veytia); y la tercera, conformada por liberales del XIX activos en la construcción de una república restaurada (Bustamante, Alamán, Ramírez, Barreda, Flores y Ruiz) y una nación proyectada por el cambio del antiguo al nuevo régimen (Chávez y Larroyo).

A finales del siglo XIX, el Positivismo sintetizó parte del legado historiográfico-educativo previo y encontró condiciones favorables al interior de las modernas universidades y escuelas normales. Recibidas desde los inicios de la vida colonial, las Antigüedades Mexicanas fueron para la gran mayoría de nuestros prehistóricos historiadores de la educación un semillero único de formación política, generalmente compatible con la memoria del poder y moderadamente crítica con ella. Inspirados en la tesis de Matute, hemos validado históricamente un horizonte de tradición genuino del pensamiento historiográfico mexicano. Ante la carencia de una sólida comunidad de historiadores de la educación, como la existente, nuestros antiguos historiadores de la educación dialogaron consigo mismos en un diálogo de vivos y muertos.

Sumado a las atinadas deudas señaladas por historiadoras como Susana Quintanilla, hemos señalado otro tipo de investigaciones por realizarse y que pueden abordarse de múltiples formas, siempre y cuando se pondere el conocimiento de un pensamiento plural cuyo legado no se limitó a escribir monografías o comentarios históricos aislados. Solo en ese sentido, hemos quedado satisfechos con el planteamiento de preguntas producidas por nuestra categoría propuesta, prehistoria de la Historiografía de la educación en México y la subsecuente clasificación (Temprana, Alta y Baja) inspirada en el medievalista e historiador de las ideas José Luis Romero. El estudio del pensamiento historiográfico-educativo exige cuestionar los consensos sobre la profesionalización del campo, porque sus límites pueden inhibir su comprensión.

Asimismo, hemos mostrado que este pensamiento no es exclusivo de los siglos XIX y XX. Basándonos en historiadores como León-Portilla, Achim, Moreno y de los Arcos y Matute, validamos la hipótesis de la existencia de historiadores de la educación mesoamericanos, novohispanos y mexicanos, sólo en sentido lato porque la profesionalización si pertenece a siglos recientes. Tan absurdo sería afirmar que el campo ya existía antes del siglo XIX, como negar la existencia de pensamiento historiográfico-educativo propio, pues éste no nació por arte de magia cuando aparecieron instituciones preservadoras del patrimonio históricoeducativo mexicano. En ese sentido, un rasgo epistémico más o menos común en tal pensamiento fue el estudio de las Antigüedades Mexicanas, vistas por la mayoría de sus exponentes como fuente histórica prístina que daba sentido al relativo nacionalismo conectado con los intereses hegemónicos del gobierno en turno (a excepción de Alamán y Chávez). El estudio de dicho pensamiento exige una crítica de su función social. Igualmente, juzgar 
exitosa o fracasada a la evangelización tuvo diversos fines y generó disensos no resolutivos que dieron pauta a varias interpretaciones, hasta que la profesionalización permitió elevar la rigurosidad teórico-metodológica y perfiló la creación de un campo profesional.

En torno a dicho pensamiento, es preciso estudiar las fuentes teóricas, metodológicas y filosóficas con las que se reelaboraron saberes históricos en tanto respuestas a las crisis políticas y culturales vividas por historiadores novohispanos y mexicanos. Desde Bustamante hasta Chávez, el último periodo prehistórico conectó su visión historiográfico-educativa con la perspectiva jesuita, representada por Clavijero y Veytia, y que es un puente con los primeros historiadores de la educación. Dadora de sentido a una moderna educación de la juventud, nuestro pensamiento historiográfico-educativo dejó huellas conceptuales muy sedimentadas, pero que crecieron en campo fértil en su época. Es preciso realizar análisis y críticas originales del estudio de la vida histórico-educativa en cada generación aquí indicada, no obstante que el esquema propuesto está abierto a reformulaciones. Sólo investigaciones posteriores ayudarán a refutar lo que tenga de refutable y confirmar lo que tenga de confirmable, aunque el estudio de la historicidad del campo historiográfico-educativo mexicano ya es una tarea impostergable.

\section{Referencias hemerográficas}

García Cerda, Pólux (2019), "El laberíntico mundo de la Historia General de la Educación y la Pedagogía. Una introducción" en Correo del maestro, núm. 286, ene., México, pp. 39-49.

- (2020), "El laberíntico mundo de la Historia de la Educación y la Pedagogía en México. Una introducción" en Correo del maestro, México, núm. 283, ago., México, pp. 40-51.

García Loaeza, Pablo (2007), "La historia al servicio de la patria: el patriota mexicano Carlos María de Bustamante (siglo XIX) edita al historiador novohispano Fernando de Alva Ixtlilxóchitl (siglo XVII)" en Colonial Latin American Historical Review, vol. 16, No. 1, México.

Matute, Álvaro (2010), Historia de la escritura de la historia en México. Curso impartido 26 al 30 de abril en el MUAC (Consulta: https://grandesmaestros.unam.mx/curso/historia-de-la-escritura-de-lahistoria-en-mexico/\#1559174071932-780dad76-24a00166-044b ).

Moreno y de los Arcos, Roberto (1972), "Notas críticas que escribió el Bachiller don José Antonio Alzate sobre la Historia Antigua de México del Abate don Francisco Javier Clavijero" en Estudios de cultura náhuatl, vol. X, México, pp. 85-120.

Navarrete, Fernando (1999), "Las fuentes indígenas más allá de la dicotomía entre historia y mito" en Estudios de cultura náhuatl, núm. 30, México, pp. 231-256.

\section{Referencias bibliográficas}

Achim, Miruna e Irina Podgorny (ed.) (2014), Museos al detalle. Colecciones, antigüedades e historia natural, 1790-1870, Prohistoria ediciones, Rosario.

Acosta, Joseph de (1590), Historia natural y moral de las indias, Casa de Juan de León, Sevilla. 
Arteaga, Belinda (1999) "Los caminos de Clío. Paradigmas y debates de la historiografía contemporánea", apud Mario Aguirre y Valentina Cantón, (coords.) (1999), Inventio varia: textos de, desde y para la historia de la educación en México, T. 1, UPN, México, pp. 47-80.

Alamán, Lucas (1889), Obras de D. Lucas Alamán. Disertaciones sobre la historia de Méjico, Tomo III, Imp. de V. Agüeros, México.

Albiñana, Salvador (1998), "Notas sobre universitarios y libros novohispanos en el siglo XVI" apud Pedro Ruiz, (comp.), Doctores y escolares. I/ Congreso internacional de historia de las universidades hispánicas. Volumen I, Universitat de Valencia, Valencia, pp. 37-48.

Alva Ixtlilxóchitl, Fernando (1975), Obras históricas, vol. II, UNAM, México.

Barreda, Gabino (1992), Estudios, UNAM, México.

Becerra, José (1963), La organización de los estudios en la Nueva España, Cultura, México.

Bustamante, Carlos María de (1984), Don José María Morelos. Elogio histórico. La abispa de Chilpancingo, Joaquín Porrúa, México.

(1826), Tezcoco en los tiempos de sus antiguos reyes, ó sea, Relación toma de los manuscritos inéditos de Boturini; redactados por el Lic. D. Mariano Veytia. Publicalos con notas y adiciones para estudio de la juventud mexicana, Carlos María de Bustamante, Imp. De Mariano Galván, México.

Chávez, Ezequiel, "La educación nacional", apud Justo Sierra (ed.) (2005), México. Su evolución social, M. A. Porrúa, México.

Ezequiel A. Chávez, México.

(1994), Educación y evangelización, Jus/El Colegio Nacional, México.

Clavijero, Francisco (1963), Historia antigua de México, Porrúa, México.

Durán, Diego (1880), Historia de la Nueva España. Islas de tierra firme, Imp. de Ignacio México, Escalante.

Eguiara y Eguren, José de (1986), Biblioteca Mexicana, UNAM, México.

Gonzalbo, Pilar (1990), Historia de la educación en la época colonial. El mundo indígena, COLMEX, México.

González, Enrique (2017), El Poder de las Letras. Por una historia social de las universidades de la América hispana en el periodo colonial, UNAM, México.

González, Enrique y Víctor Gutiérrez (2017), Juan de Palafox y Mendoza: Constituciones para la Real Universidad de México (1645), UNAM/EyC/BUAP, México

González, Luis (2002), "De la múltiple utilización de la historia”, apud Carlos Pereyra, et al., Historia ¿Para qué?, Siglo XXI, México.

Hernández, Ascensión (2001), "Introducción", apud Francisco Hernández (2001), Antigüedades de la Nueva España, Dastin, Madrid.

Larroyo, Francisco (1978), Historia comparada de la educación en México, Porrúa, México.

León-Portilla, Miguel (2017), Filosofía náhuatl estudiada desde sus fuentes, UNAM/ Fideicomiso Felipe Teixidor, México.

(2011), Los antiguos mexicanos a través de sus crónicas y cantares, FCE México.

Livio, Tito (2000), Historia de Roma desde su fundación, Gredos, Madrid.

López Caballero, Paula (2011), "De cómo el pasado prehispánico se volvió el pasado de todos los mexicanos", apud Pablo Escalante, (coord.) (2011), La idea de nuestro patrimonio histórico y cultural, Consejo Nacional para la Cultura y las Artes, México, pp. 137-151.

Matute, Álvaro (1999), "La profesionalización del trabajo histórico en el siglo XX", apud Miguel Carbonell (et al) (1999), México en el siglo XX, AGN, México.

-(2015), La teoría de la historia en México (1940-1968), FCE, México.

Mendieta, Jerónimo de (1870), Historia eclesiástica indiana, Antigua Librería, México.

Moreno y de los Arcos, Enrique (1993), Principios de pedagogía asistemática, UNAM, México.

Ortega y Medina, Juan (1992), Polémicas y ensayos mexicanos en torno a la historia, UNAM, México. 
Pérez, Teresa de Jesús (1998), Francisco Larroyo y la historia de la educación en México: configuración de un campo disciplinario, UNAM, México.

Quintanilla, Susana, (coord.) (1995), Teoría, campo e historia de la educación. La investigación educativa en los ochenta, COMIE, México.

Ramírez, Ignacio (1889), Obras de Ignacio Ramírez. Tomo II. Economía politica. Cuestiones políticas y sociales, Oficina Tip. de la Secretaría de Fomento, México.

Romero, José Luis (2008), La vida histórica, Siglo XXI, México.

(2013), La Edad Media, FCE, México [edición electrónica].

Ruiz, Luis (1986), Tratado elemental de pedagogía, UNAM, México.

Sahagún, Bernardino de (1938), Historia general de las cosas de la Nueva España, Tomo I, Pedro Robredo, México.

Sigüenza, Carlos de (1995), Parayso occidental: plantado y cultivado por la liberal benéfica mano de los muy catholicos y poderosos reyes de España, nuestros señores en su magnífico Real Convento de Jesús María de México, UNAM, México. 